\title{
Antioxidant and antimicrobial activities of bitter and sweet apricot (Prunus armeniaca L.) kernels
}

\author{
D. Yiğit ${ }^{1}$, N. Yiğit' ${ }^{2}$ and A. Mavi ${ }^{3}$ \\ ${ }^{1}$ Department of Science Education, Education Faculty, Erzincan University, Erzincan, Turkey \\ ${ }^{2}$ Health Services Vocational Training School, Medical Laboratory Department, Atatürk University, \\ Erzurun, Turkey \\ ${ }^{3}$ Kazim Karabekir Education Faculty, Atatürk University, Erzurum, Turkey \\ Correpondence to: D. Yiğit, Department of Science Education, Education Faculty, Erzincan University, \\ Erzincan, Turkey \\ Fax: +90-44-6223-1901. E-mail: demyigit@hotmail.com
}

\begin{abstract}
The present study describes the in vitro antimicrobial and antioxidant activity of methanol and water extracts of sweet and bitter apricot (Prunus armeniaca L.) kernels. The antioxidant properties of apricot kernels were evaluated by determining radical scavenging power, lipid peroxidation inhibition activity and total phenol content measured with a DPPH test, the thiocyanate method and the Folin method, respectively. In contrast to extracts of the bitter kernels, both the water and methanol extracts of sweet kernels have antioxidant potential. The highest percent inhibition of lipid peroxidation (69\%) and total phenolic content (7.9 $\pm 0.2 \mu \mathrm{g} / \mathrm{mL}$ ) were detected in the methanol extract of sweet kernels (Hasanbey) and in the water extract of the same cultivar, respectively. The antimicrobial activities of the above extracts were also tested against human pathogenic microorganisms using a disc-diffusion method, and the minimal inhibitory concentration (MIC) values of each active extract were determined. The most effective antibacterial activity was observed in the methanol and water extracts of bitter kernels and in the methanol extract of sweet kernels against the Gram-positive bacteria Staphylococcus aureus. Additionally, the methanol extracts of the bitter kernels were very potent against the Gram-negative bacteria Escherichia coli $(0.312 \mathrm{mg} / \mathrm{mL}$ MIC value). Significant anti-candida activity was also observed with the methanol extract of bitter apricot kernels against Candida albicans, consisting of a $14 \mathrm{~mm}$ in diameter of inhibition zone and a $0.625 \mathrm{mg} / \mathrm{mL} \mathrm{MIC}$ value.
\end{abstract}

Key words: Apricot (Prunus armeniaca L.) kernels; Antioxidant activity; Antimicrobial activity; Total phenolic compounds

Received August 2, 2008. Accepted February 9, 2009

\section{Introduction}

In the past few years, there has been a renewed interest in evaluating the antioxidant content and distribution patterns of fruits and vegetables. This change occurred after it was discovered that antioxidant phytonutrients (carotenoid and phenolics) are important for two main reasons. First, they are responsible for the sensory properties of food and second, they have protective activity against a variety of degenerative diseases $(1,2)$.

Currently, there is overwhelming evidence indicating that free radicals cause oxidative damage to lipids, pro- teins and nucleic acids. Free radicals may lie at the heart of the etiology or of the natural history of a number of diseases, including cancer and atherosclerosis (3-5). Therefore, antioxidants, which can neutralize free radicals, may be of central importance in the prevention of these diseases (6).

Fruits and vegetables contain many different antioxidant components. For example, some flavonoids (including flavones, isoflavones, flavonones, anthocyanins, catechin, and isocatechin) that are frequent components of the human diet have demonstrated strong antioxidant activities (7). In fact, higher plants exhibit significant potency 
against human bacterial and fungal pathogens. Apart from being the primary food source of some essential nutrients, fruits and vegetables also contain a variety of bioactive components, which might have other beneficial health effects (8).

The apricot (Prunus armeniaca L.) is a member of the Rosaceae family. Apricot fruit, being a rich source of vitamins and minerals, is one of the most familiar crops worldwide. Apricot trees are not ubiquitous since they can only grow in certain regions where the environmental conditions are favorable (9). The apricot is native to China and Japan, but is also cultivated in the warmer temperate regions of the world, including Turkey, through southern Europe, South Africa and Australia. In Turkey, the apricot is grown mainly in Malatya and Erzincan where the climate permits economic production (10).

The apricot has been used in folk medicine as a remedy for various diseases. A decoction of the plant bark has functioned as an astringent to soothe irritated skin. Other uses for apricots in folk medicine include treatment of hemorrhages, infertility, eye inflammation, and spasm. Apricot kernel paste can heal vaginal infections. The kernel oil has been used in cosmetics and as a pharmaceutical agent (laxative and expectorant). In very small amounts, the toxic hydrogen cyanide present in bitter apricot kernels has been prescribed for asthma, cough and constipation (11).

The fresh apricot fruit contains carbohydrates, vitamins $\mathrm{C}$ and $\mathrm{K}, \beta$-carotene, niacin, and thiamine. Organic acids, phenols, volatile compounds, esters, and terpenoids have also been isolated $(2,12-14)$.

Apricot kernels contain a substantial amount of dietary protein (15), along with significant amounts of oil and fiber $(16,17)$. In a previous study, Femenia et al. (18) reported that sweet apricot kernels contain more oil than bitter kernels, and that oleic acid and linoleic acid correspond to approximately $92 \mathrm{~g} / 100 \mathrm{~g}$ of the total fatty acids present.

Apricot kernels, depending on the variety, contain the toxic cyanogenic glycoside amygdalin (19). Amygdalin can be hydrolyzed to form glucose, benzaldehyde and hydrocyanic acid. Enzymatic release of cyanide occurs in the presence of $\beta$-glucoronidase, an enzyme found in the human intestine (20).

Numerous reports concerning the physicochemical characteristics of apricot seed oils are available in the literature $(2,21,22)$, but little information is available concerning the in vitro antioxidant activities of these oils (23). Similarly, the antimicrobial activities of apricot kernels have been poorly studied (24), and the lack of studies concerning the antibacterial and antifungal activity of the kernels have stimulated the present research.

Thus, the objective of the present study was to deter- mine the antioxidant and antimicrobial activities of methanol and water extracts of both bitter and sweet kernels of $P$. armeniaca $\mathrm{L}$.

\section{Material and Methods}

\section{Preparation of extracts}

Apricot fruits ( $P$. armeniaca L.) were collected at their optimum commercial maturity when enologically ripe in Uzumlu Town, Erzincan, Turkey. Bitter kernels belong to wild apricot fruits locally known as Zerdali, and sweet kernels are locally known as Hasanbey. The fresh fruit samples were transported to the laboratory where the stones were removed, and individual stones were hammered to obtain the seed kernel. Next, the skin was removed, and the kernels were dried on the bench and then ground to a powder using an electric blender. Powdered kernels were extracted with methanol in a Soxhlet apparatus for $24 \mathrm{~h}$. Subsequently, the methanol was evaporated with a rotary evaporator. After evaporation of the solvent, the w/w yield from the dry starting material was 14.3 and $12.6 \%$ for Hasanbey and Zerdali kernels, respectively. Water extracts were also prepared by adding $20 \mathrm{~g}$ powdered material to $200 \mathrm{~mL}$ boiling water in a glass flask, and the solutions were incubated at room temperature for $2 \mathrm{~h}$ on a rotating shaker $(200 \mathrm{rpm})$. The mixture was filtered through Whatman (No. 1) filter paper, and the filtrate was lyophilized. The kernel extract yields were 8.2 (w/ w) and $7.9 \%(w / w)$ for the Hasanbey and Zerdali cultivars, respectively. All extracts were stored in a freezer at $-24^{\circ} \mathrm{C}$ until use.

\section{Antimicrobial activity}

Tests were carried out on clinical isolates of 96 bacterial strains belonging to five bacterial species (Enterobacter aerogenes, Escherichia coli, Proteus mirabilis, Pseudomonas aeruginosa, and Staphylococcus aureus) and 91 Candida strains belonging to nine yeast species (Candida albicans, C. glabrata, C. guilliermondii, C. kefyr, C. krusei, C. parapisilosis, C. pseudotropicalis, C. tropicalis, and Geotrichum candidum). Microorganisms were provided by the Department of Clinical Microbiology, Faculty of Medicine, Erzurum. The Candida isolates were identified using standard taxonomic procedures, including analysis of germ tube production, microscopic appearance on cornmeal agar with Tween-80, the production of chlamydospores, colony morphology, and pigment production on chromogenic medium. The identification was confirmed by the API 32C AUX (BioMeriux, Marcy-l'Etoile, France) identification system for yeast.

The Gram-negative bacteria were submitted to tests including the indol test, motility, methyl red, hydrogen 
sulfide production, urease and phenylalanine decarboxylase production, growth in Simmons citrate and fermentation of glucose, lactose, saccharose, and mannitol. The colonies with a Gram-positive coccus morphology isolated in blood agar were submitted to tests of colony morphology, pigment production, Gram stain, and catalase and coagulase production.

Disc-diffusion assay. The dried methanol and water extracts were dissolved in the extraction solvent (methanol or sterile distilled water) to a final concentration of $30 \mathrm{mg} /$ $\mathrm{mL}$. Antimicrobial tests were than carried out using a discdiffusion method (25) with a suspension containing $10^{8}$ colony forming units $/ \mathrm{mL}$ of bacteria and $10^{6}$ colony forming units $/ \mathrm{mL}$ of yeast spread on nutrient agar (Oxoid, USA). Extracts were applied to the discs (6 $\mathrm{mm}$ in diameter) and allowed to soak in, and were then placed on the inoculated nutrient agar. Negative controls were prepared using the same solvents as employed to obtain the extracts. As positive controls, ofloxacin ( $5 \mu \mathrm{g}$, Oxoid) was used for Gram-positive bacteria, cefaperazone-sulbactam (105 $\mu \mathrm{g}$, Oxoid) for Gram-negative bacteria and amphotericin B (30 $\mu \mathrm{g}$, Sigma) for Candida spp. The inoculated plates were incubated at $37^{\circ} \mathrm{C}$ for $24 \mathrm{~h}$ for clinical bacterial strains and at $35^{\circ} \mathrm{C}$ for $48 \mathrm{~h}$ for yeast. Antimicrobial activity was evaluated by measuring the inhibition zone against test microorganisms.

The minimal inhibitory concentration (MIC) was also determined for each microorganism that was sensitive to the methanol and/or water extracts in the disc-diffusion assay. MIC values for extracts against microbial strains were determined based on a micro-well dilution method (26). The inoculations of microorganisms were prepared from 12-h broth cultures, and suspensions were adjusted to 0.5 McFarland standard turbidity. First, the extracts were dissolved in $10 \%$ dimethyl sulfoxide in water to a dilution of $5 \mathrm{mg} / \mathrm{mL}$, and serial 2-fold dilutions were prepared in a sterile test tube containing nutrient broth for a specific range of concentrations $(0.078-5 \mathrm{mg} / \mathrm{mL})$. The $96-$ well plates were prepared by dispensing $95 \mu \mathrm{L}$ nutrient broth and $5 \mu \mathrm{L}$ of the inocula into each well. A volume of $100 \mu \mathrm{L}$ from each extract prepared at the highest concentration was added to the first well, and then $100 \mu \mathrm{L}$ from each serial dilution was transferred to other consecutive wells. The plates were covered with a sterile plate sealer and then incubated for $24 \mathrm{~h}$ (for bacterial strains) and $48 \mathrm{~h}$ (for fungal strains). The MIC was defined as the lowest concentration of the extract that would inhibit the growth of the microorganism.

\section{Antioxidant activity}

Antioxidant activity was determined by the thiocyanate method (27). Briefly, stock extract solutions were prepared at $2 \mathrm{mg} / \mathrm{mL}$ concentration of required stock solutions and mixed with $2.5 \mathrm{~mL} 20 \mathrm{mM}$ linoleic acid emulsion (Fluka, Germany) containing an equal weight of Tween-20 (Sigma, USA) in phosphate-buffered saline, pH 7.4 (Sigma). The final volume was adjusted to $5 \mathrm{~mL}$ with $20 \mathrm{mM}$ phosphate-buffered saline, $\mathrm{pH} 7.4$, in a test tube and incubated in the dark at $40^{\circ} \mathrm{C}$. The final concentration of the extracts was $100 \mu \mathrm{g} / \mathrm{mL}$. Butylated hydroxytoluene (Sigma) was used as positive control $(100 \mu \mathrm{g} / \mathrm{mL})$. The amount of peroxide was determined by measuring absorbance at 500 $\mathrm{nm}$ after coloring yellow with $\mathrm{FeCl}_{2}$ and thiocyanate during a 24-h incubation. Lower absorbance indicates higher antioxidant activity. To eliminate the solvent effect, the same amount of solvent that was used to prepare the solutions of test samples was added to the control test sample, which contained the linoleic acid emulsion. Measurements of antioxidant activity were carried out in three experimental replicates, and values are reported as the average of three replicates. This activity is reported as percent lipid peroxidation compared to the solvent control.

\section{DPPH radical-scavenging activity}

Experiments were performed as described previously (28). Briefly, a $0.5 \mathrm{mM}$ 2,2-diphenyl-1-picrylhydrazyl (DPPH; Fluka) radical solution was prepared in methanol, and 1 $\mathrm{mL}$ of this solution was mixed with $3 \mathrm{~mL}$ of the sample solution. Final concentrations of essential oils were 100 and $300 \mu \mathrm{g} / \mathrm{mL}$. Butylated hydroxytoluene was used as a positive control at the same concentration. After incubation for $30 \mathrm{~min}$ in the dark, absorbance at $517 \mathrm{~nm}$ was measured. A decreasing absorbance of the DPPH solution indicates an increase in DPPH radical scavenging activity. This activity is reported as a percent of DPPH radical scavenging.

The control contained $1 \mathrm{~mL}$ DPPH solution mixed with $3 \mathrm{~mL}$ ethanol. DPPH radical scavenging activity was measured in duplicate, and the values are reported as the average.

\section{Determination of total phenolic compounds}

Antioxidant compounds generally contain phenolic group(s). Because of this, the amounts of phenolic compounds in each extract were compared. The analysis was performed as described previously (27). Aliquots of the extract were diluted to $4 \mathrm{~mL}$ in water, $0.25 \mathrm{~mL}$ FolinCiocalteu reagent (Fluka) was added and after 3 min 0.75 $\mathrm{mL}$ of a $2 \% \mathrm{Na}_{2} \mathrm{CO}_{3}$ solution was added. Subsequently, the mixture was transferred to a shaker for $2 \mathrm{~h}$ at room temperature and absorbance at $760 \mathrm{~nm}$ was measured. The amount of total phenolic compounds was calculated 
for two different experiments, and the values reported are the average of two replicates. Gallic acid was used as the standard for a calibration curve. The phenolic compound content was reported as gallic acid equivalents.

\section{Statistical analysis}

Statistical analyses were performed using the SPSS 12.0 software. To identify correlations between lipid peroxide inhibition, radical scavenging activity and total phenolic content, the data were analyzed by bivariate correlation using the Pearson correlation test. Values of $P<0.05$ were considered to be statistically significant.

\section{Results and Discussion}

\section{Antioxidant activity}

The highest percent inhibition of lipid peroxidation was $68.6 \% / 100 \mu \mathrm{g}$ solid in methanol extracts of the sweet kernel (Hasanbey). This was followed by the water extract from the same cultivar, which demonstrated $66.3 \%$ inhibition. The lowest activities were detected in the methanol and water extracts of a bitter kernel with 3.7 and $20.2 \%$ inhibition, respectively.

The DPPH radical scavenging activities of water and methanol extracts from apricot cultivars are shown in Figure 1. At a concentration of $100 \mu \mathrm{g} / \mathrm{mL}$, the water and methanol extracts of the sweet kernel exhibited 89.9 and $87.7 \%$ scavenging activity, respectively. However, at a concentration of $300 \mu \mathrm{g} / \mathrm{mL}$, the respective activities were 89.9 and $92.2 \%$. There was no noticeable effect of extract concentration for these extracts. Unlike sweet kernel extracts, there was no detectable activity in the bitter kernel extracts at the concentrations studied $(100-300 \mu \mathrm{g} / \mathrm{mL})$.

In order to determine the amount of phenolic compounds present in the extracts, the absorbance of the extract solutions was measured after incubating the samples with the Folin-Ciocalteu reagent. Like radicalscavenging activities and percent lipid peroxidation inhibition, the contents of phenolic compounds of both methanol and water extracts of the bitter kernel were lower than sweet kernel extracts, each containing $100 \mu \mathrm{g} / \mathrm{mL}$ solid (Table 1). The highest phenolic content $(7.9 \pm 0.2 \mu \mathrm{g} / \mathrm{mL})$ was detected in the water extract of a sweet apricot kernel, while the lowest phenolic content was $0.4 \pm 0.1 \mu \mathrm{g} / \mathrm{mL}$ in the water extract of the bitter apricot kernel.

According to the Pearson correlation test, there was a statistically significant correlation between DPPH radical scavenging and total phenolic compounds $(r=0.975, \mathrm{P}<$ 0.01 ), between peroxide inhibition and total phenolic compounds $(r=0.942, P<0.05)$, and between lipid peroxide

Table 1. Total phenolic compounds in methanol and water extracts of sweet and bitter apricot kernels.

\begin{tabular}{lcc} 
Extract & $\begin{array}{c}\text { Absorbance } \\
(760 \mathrm{~nm})\end{array}$ & $\begin{array}{c}\text { Gallic acid } \\
\text { equivalent } \\
(\mu \mathrm{g} / \mathrm{mL})\end{array}$ \\
\hline Control & 0.003 & - \\
Water extract of bitter kernels & 0.11 & $0.4 \pm 0.1$ \\
Methanol extract of bitter kernels & 0.12 & $0.5 \pm 0.0$ \\
Water extract of sweet kernels & 2.04 & $7.9 \pm 0.2$ \\
Methanol extract of sweet kernels & 1.45 & $5.7 \pm 0.3$
\end{tabular}

One hundred micrograms extract solid/mL was used for all assays. The control contained no extract.

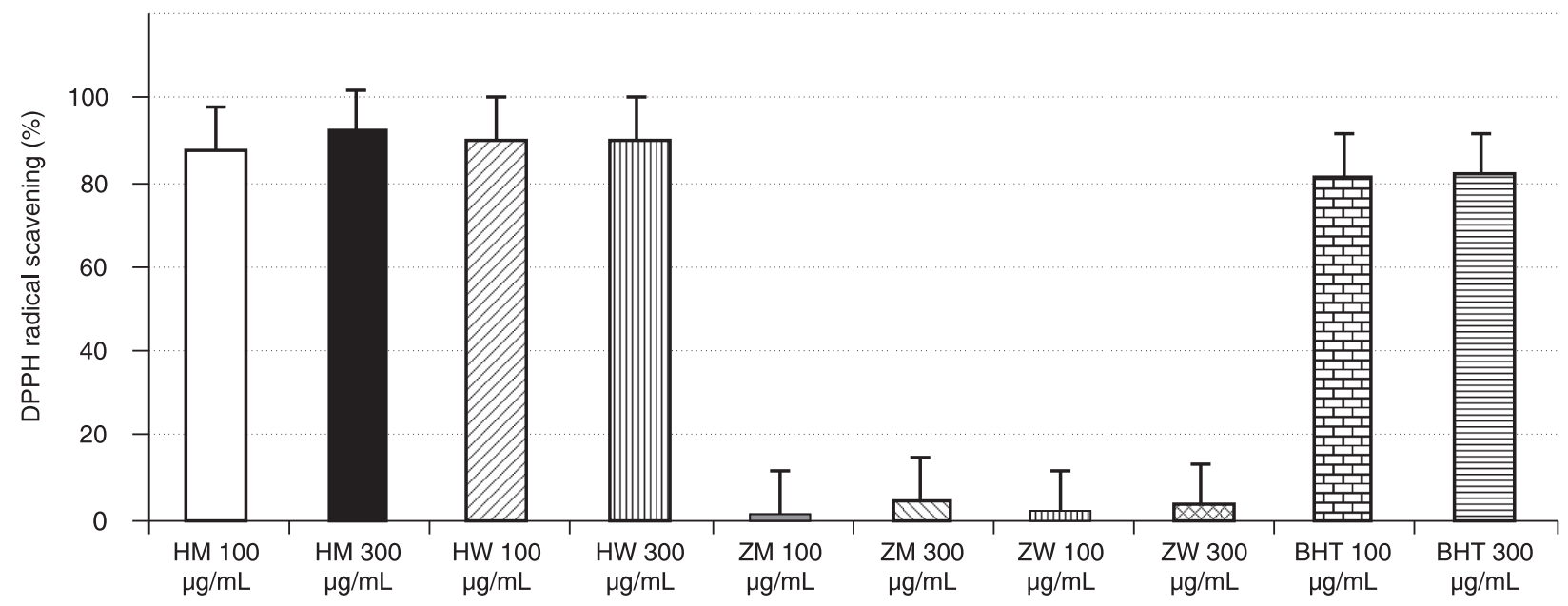

Figure 1. 2,2-Diphenyl-1-picrylhydrazyl (DPPH) radical scavenging activity. $\mathrm{H}=$ Hasanbey apricot cultivar; $\mathrm{Z}=$ Zerdali apricot cultivar; $\mathrm{M}=$ methanol extract; $\mathrm{W}=$ water extract; $\mathrm{BHT}$ = butylated hydroxytoluene 
inhibition and DPPH radical scavenging $(r=0.979, \mathrm{P}<$ 0.05).

\section{Antimicrobial activities}

Table 2 shows the antimicrobial activities of methanol and water extracts of bitter (Zerdali) and sweet (Hasanbey) apricot cultivar kernels against clinical isolates of human pathogenic bacteria and yeast. The microorganisms examined in the present study belong to five bacteria and nine yeast species. The antimicrobial potency was quantitatively assessed (Table 2), and each active extract was used to calculate the MIC (Table 3).

The water and methanol extracts of bitter and sweet kernels showed antimicrobial activity against clinical isolates of microorganisms from six species, with inhibition zones ranging from 8 to $15 \mathrm{~mm}$ (Table 2). The results confirmed that both sweet and bitter kernels of apricot are potentially rich sources of antimicrobial agents. However, both fruit kernel extracts exhibited similar characteristics in their activity against test microorganisms, with differences being observed for only two microorganisms, $P$. mirabilis and C. glabrata.

None of the extracts exhibited antimicrobial activity against eight of the fourteen microorganisms, Enterobacter aerogenes, $P$. aeruginosa, C. guilliermondii, C. kefyr, C. krusei, C. pseudotropicalis, C. tropicalis, and G. candidum.

The highest activity was obtained with both methanol and water extracts of bitter kernels, which showed broadspectrum antimicrobial activity against Gram-positive, Gram-negative and Candida strains. Specifically, these extracts produced inhibition zones of $8-15 \mathrm{~mm}$ and MIC values of $0.312-2.5 \mathrm{mg} / \mathrm{mL}$ (Tables 2 and 3).

The higher activity of bitter kernels, with inhibition zones of more than $12 \mathrm{~mm}$, was observed for both the methanol and water extracts against $S$. aureus and $E$. coli and in methanol extracts against $C$. albicans. However, the water extracts exhibited activity against $P$. mirabilis with a 12-mm inhibition zone and a $0.625 \mathrm{mg} / \mathrm{mL}$ MIC value. Methanol extracts of the bitter kernel had anticandidal activity against $C$. glabrata, with a $10-\mathrm{mm}$ inhibition zone and a $1.25 \mathrm{mg} / \mathrm{mL}$ MIC value. However, none of the sweet kernel extracts had any antimicrobial activity against these microorganisms.

Similar to the bitter kernel apricot extracts, higher activity was detected in sweet kernel extracts against $E$. coli with 13-mm inhibition zones. Additionally, moderate activity of sweet kernels, with an inhibition zone of more than 7 $\mathrm{mm}$, was documented against $S$. aureus, $C$. albicans and C. parapisilosis (Table 2).

The results obtained in the current study indicate that the candidal strains are resistant to both kernel extracts screened.

Table 2. Antimicrobial activity of methanol and water extracts of bitter (Zerdali) and sweet (Hasanbey) apricot (Prunus armeniaca L.) kernels against some clinical isolates.

\begin{tabular}{|c|c|c|c|c|}
\hline \multirow[t]{3}{*}{ Microorganism } & \multicolumn{4}{|c|}{ Inhibition zone diameter (mm) } \\
\hline & \multicolumn{2}{|c|}{ Methanol extracts } & \multicolumn{2}{|c|}{ Water extracts } \\
\hline & Hasanbey & Zerdali & Hasanbey & Zerdali \\
\hline Enterobacter aerogenes & - & - & - & - \\
\hline Escherichia coli & $13 \pm 1.7$ & $15 \pm 1.5$ & $13 \pm 1.4$ & $15 \pm 2.2$ \\
\hline Proteus mirabilis & - & - & - & $12 \pm 2.1$ \\
\hline Pseudomonas aeruginosa & - & - & - & - \\
\hline Staphylococcus aureus & $12 \pm 1.9$ & $15 \pm 2.2$ & $10 \pm 1.6$ & $13 \pm 2.3$ \\
\hline Candida albicans & $8 \pm 1.5$ & $14 \pm 1.9$ & $8 \pm 1.2$ & $10 \pm 2$ \\
\hline Candida glabrata & - & $10 \pm 2.2$ & - & - \\
\hline Candida guillermondii & - & - & - & - \\
\hline Candida kefyr & - & - & - & - \\
\hline Candida krusei & - & - & - & - \\
\hline Candida parapisilosis & $11 \pm 1.9$ & $8 \pm 2.1$ & $11 \pm 2.6$ & $10 \pm 2.4$ \\
\hline Candida pseudotropicalis & - & - & - & - \\
\hline Candida tropicalis & - & - & - & - \\
\hline Geotrichum candidum & - & - & - & - \\
\hline
\end{tabular}

- = not active, inhibition zone was no greater than $6 \mathrm{~mm} ; 7-12 \mathrm{~mm}=$ moderately active; $>12=$ highly active. Negative controls (methanol and water) showed no inhibiting effect. Inhibition diameters of positive controls ranged from 18 to $20 \mathrm{~mm}$ for $5 \mu \mathrm{g}$ ofloxacin, $19-22 \mathrm{~mm}$ for $105 \mu \mathrm{g}$ cefaperazone and $12-15 \mathrm{~mm}$ for $30 \mu \mathrm{g}$ amphotericin $\mathrm{B}$, respectively. 
Table 3. Minimum inhibitory concentration (MIC) values $(\mathrm{mg})$ of methanol and water extracts of solid/mL bitter (Zerdali) and sweet (Hasanbey) apricot (Prunus armeniaca L.) kernels against bacteria and yeast tested in the microdilution assay.

\begin{tabular}{|c|c|c|c|c|}
\hline \multirow[t]{3}{*}{ Microorganism } & \multicolumn{4}{|c|}{ Minimum inhibition concentration $(\mathrm{mg} / \mathrm{mL})$} \\
\hline & \multicolumn{2}{|c|}{ Methanol extracts } & \multicolumn{2}{|c|}{ Water extracts } \\
\hline & Hasanbey & Zerdali & Hasanbey & Zerdali \\
\hline Escherichia coli & 0.312 & 0.312 & 0.625 & 0.625 \\
\hline Proteus mirabilis & - & - & - & 0.625 \\
\hline Staphylococcus aureus & 0.312 & 0.312 & 1.25 & 0.312 \\
\hline Candida albicans & 2.5 & 0.625 & 5 & 2.5 \\
\hline Candida glabrata & - & 1.25 & - & - \\
\hline Candida parapisilosis & 1.25 & 2.5 & 2.5 & 2.5 \\
\hline
\end{tabular}

- = extract not tested. MIC values of positive controls ranged from 0.12 to $1 \mu \mathrm{g} / \mathrm{mL}$ for $5 \mu \mathrm{g}$ ofloxacin, 0.12 to $0.5 \mu \mathrm{g} / \mathrm{mL}$ for $105 \mu \mathrm{g}$ cefaperazone, and 0.5 to $1 \mu \mathrm{g} / \mathrm{mL}$ for $30 \mu \mathrm{g}$ amphotericin $B$, respectively.

Similarly, it has been previously reported that fungi are more resistant than bacteria to plant extracts (29-31).

The butanol extract from $P$. armeniaca fruits showed inhibitory activity on disease-causing Gram-negative bacteria (31.25-250 $\mu \mathrm{g} / \mathrm{mL}$ MIC values) and Gram-positive bacteria (125-250 $\mu \mathrm{g} / \mathrm{mL}$ MIC values). The most inhibited was Micrococcus luteus (31.25 mg/mL MIC value) (32). Different findings have been reported in another study, indicating that the essential oil of apricots had no antimicrobial activity against some bacteria and yeast (23). On the other hand, high antimicrobial activity (90\% inhibition) from the methanol extracts of Japanese apricot has been reported against Helicobacter pylori (33).

The current study revealed significant antimicrobial, particularly antibacterial, activity of the extracts of both sweet and bitter apricot kernels. Additionally, high antioxidant activity was recorded, especially in sweet kernel extracts. Although the inhibition of lipid peroxidation and the DPPH radical scavenging activities of the sweet kernel extracts were markedly higher than those of bitter kernel extracts, there were no marked differences in the antimicrobial activities of the above extracts. Therefore, we suggest that there is no clear relationship between the antioxidant activities and the antimicrobial activities of the extracts. In addition, these results indicate that apricot seeds could not only serve as a rich source of food but may also be of importance in ethno-botanical studies due to their high antioxidant and antimicrobial activities.

\section{References}

1. Flood A, Velie EM, Chaterjee N, Subar AF, Thompson FE, Lacey JV Jr, et al. Fruit and vegetable intakes and the risk of colorectal cancer in the Breast Cancer Detection Demonstration Project follow-up cohort. Am J Clin Nutr 2002; 75: 936-943.

2. Ruiz D, Egea J, Gil MI, Tomas-Barberan FA. Phytonutrient content in new apricot (Prunus armeniaca L.) varieties. Acta Horticulturae 2006; 717: 363-365.

3. Ames BN. Dietary carcinogens and anticarcinogens. Oxygen radicals and degenerative diseases. Science 1983; 221: 1256-1264.

4. Ness AR, Powles JW. Fruit and vegetables, and cardiovascular disease: a review. Int J Epidemiol 1997; 26: 1-13.

5. Poulsen HE, Prieme H, Loft S. Role of oxidative DNA damage in cancer initiation and promotion. Eur $J$ Cancer Prev 1998; 7: 9-16.
6. Wang H, Cao G, Prior RL. Total antioxidant capacity of fruits. J Agric Food Chem 1996; 44: 701-705.

7. Kris-Etherton PM, Hecker KD, Bonanome A, Coval SM, Binkoski $A E$, Hilpert KF, et al. Bioactive compounds in foods: their role in the prevention of cardiovascular disease and cancer. Am J Med 2002; 113 (Suppl 9B): 71S-88S.

8. Cos P, Vlietinck AJ, Berghe DV, Maes L. Anti-infective potential of natural products: how to develop a stronger in vitro 'proof-of-concept'. J Ethnopharmacol 2006; 106: 290302.

9. Baytop T. Türkiyede bitkilerle tedavi. Istanbul: Istanbul Eczacilik Fakültesi Yayinlari; 1999.

10. Asma BM. Geçmisten günümüze Malatyada kayisi yetistiriciligi. Izollu Dergisi 2002; 5: 18-20.

11. Chevallier A. The encyclopedia of medicinal plants. New York: DK Publishing; 1996. 
12. Riu-Aumatell M, Lopez-Tamames E, Buxaderas S. Assessment of the volatile composition of juices of apricot, peach, and pear according to two pectolytic treatments. J Agric Food Chem 2005; 53: 7837-7843.

13. Ruiz D, Egea J, Tomas-Barberan FA, Gil MI. Carotenoids from new apricot (Prunus armeniaca L.) varieties and their relationship with flesh and skin color. J Agric Food Chem 2006; 53: 6368-6374.

14. Sefer F, Misirli A, Gülcan R. A research on phenolic and cyanogenic compounds in sweet and bitter apricot kernels. Acta Horticulturae 2006; 701: 167-169.

15. Nout MJ, Tuncel G, Brimer L. Microbial degradation of amygdalin of bitter apricot seeds (Prunus armeniaca). Int $\mathrm{J}$ Food Microbiol 1995; 24: 407-412.

16. El-Aal MHA, Hamza MA, Rahma EH. Apricot kernel oil: Characterization, chemical composition and utilization in some baked products. Food Chem 1986; 19: 287-298.

17. Haciseferoǒullari H, Gezer I, Özcan MM, Asma BM. Postharvest chemical and physical mechanical properties of some apricot varieties cultivated in Turkey. J Food Engineering 2007; 78: 364-373.

18. Femenia A, Rosello C, Mulet A, Canellas J. Chemical composition of bitter and sweet apricot kernels. J Agric Food Chem 1995; 43: 356-361.

19. Gomez E, Burgos L, Soriano C, Marin J. Amygdalin content in the seeds of several apricot cultivars. J Sci Food Agric 1998; 77: 184-186.

20. Shragg TA, Albertson TE, Fisher CJ Jr. Cyanide poisoning after bitter almond ingestion. West J Med 1982; 136: 65-69.

21. Karakaya S, El SN, Tas AA. Antioxidant activity of some foods containing phenolic compounds. Int J Food Sci Nutr 2001; 52: 501-508.

22. Dragovic-Uzelac V, Delonga K, Levaj B, Djakovic S, Pospisil J. Phenolic profiles of raw apricots, pumpkins, and their purees in the evaluation of apricot nectar and jam authenticity. J Agric Food Chem 2005; 53: 4836-4842.

23. Durmaz G, Alpaslan M. Antioxidant properties of roasted apricot ( $P$. armeniaca L.) Kernel. Food Chem 2007; 100:
1177-1181

24. Hammer KA, Carson CF, Riley TV. Antimicrobial activity of essential oils and other plant extracts. J Appl Microbiol 1999; 86: 985-990.

25. Murray PR, Baron EJ, Pfaller MA, Tenover FC, Yolke RH. Manual of clinical microbiology. Washington: ASM; 1995.

26. Zgoda JR, Porter JR. A convenient microdilution method for screening natural products against bacteria and fungi. Pharm Biol 2001; 39: 221-225.

27. Yildirim A, Mavi A, Kara AA. Antioxidant and antimicrobial activities of Polygonum cognatum Meissn extracts. J Sci Food Agric 2003; 83: 64-69.

28. Mavi A, Terzi Z, Ozgen U, Yildirim A, Coskun M. Antioxidant properties of some medicinal plants: Prangos ferulacea (Apiaceae), Sedum sempervivoides (Crassulaceae), Malva neglecta (Malvaceae), Cruciata taurica (Rubiaceae), Rosa pimpinellifolia (Rosaceae), Galium verum subsp. verum (Rubiaceae), Urtica dioica (Urticaceae). Biol Pharm Bull 2004; 27: 702-705.

29. Yam TS, Shah S, Hamilton-Miller JM. Microbiological activity of whole and fractionated crude extracts of tea (Camellia sinensis), and of tea components. FEMS Microbiol Lett 1997; 152: 169-174.

30. Nostro A, Germano MP, D'angelo V, Marino A, Cannatelli MA. Extraction methods and bioautography for evaluation of medicinal plant antimicrobial activity. Lett Appl Microbiol 2000; 30: 379-384.

31. Duarte MC, Figueira GM, Sartoratto A, Rehder VL, Delarmelina C. Anti-Candida activity of Brazilian medicinal plants. J Ethnopharmacol 2005; 97: 305-311.

32. Rashid F, Ahmed R, Mahmood A, Ahmad Z, Bibi N, Kazmi SU. Flavonoid glycosides from Prunus armeniaca and the antibacterial activity of a crude extract. Arch Pharm Res 2007; 30: 932-937.

33. Miyazawa M, Utsunomiya $\mathrm{H}$, Inada K, Yamada T, Okuno $\mathrm{Y}$, Tanaka $\mathrm{H}$, et al. Inhibition of Helicobacter pylori motility by (+)-Syringaresinol from unripe Japanese apricot. Biol Pharm Bull 2006; 29: 172-173. 